\title{
Contribution of modeling to the knowledge of trace elements behaviour and speciation in estuaries
}

\author{
J.-L. Gonzalez, C. Dange and B. Thouvenin
}

IFREMER, DEL, Département Polluants Chimiques, Centre de La-Seyne-sur-Mer, ZP de Brégaillon, BP. 330, 83507 La-Seyne-sur-Mer, France

\begin{abstract}
Geochemical models are excellent tools for the understanding of trace elements dynamics, in particular in complex environments like estuaries. Their aim is to reproduce numerically the biogeochemical processes observed in the field or laboratory. The development and the use of this kind of tool requires :

- in-situ data on the distribution in space and time of the elements studied and relationship with the environmental variables.

- experimental data (mainly based on the use of radioactive analogues of the studied elements) for evaluation of model parameters and the validation of model assumptions.

The model must be capable not only of reproducing the distribution of metals between the dissolved and particulate phases, but also of evaluating the concentrations of various chemical species (especially those which are most bioavailable). The approach presented treats adsorption processes as a formation of complexes with functional surface groups (surface complexation model). The calculation of chemical species takes into account the presence of dissolved ligands. The model can integrate several types of "natural" particles (oxydes, particulate organic matter) and different types of surface sites. This approach requires the evaluation of various parameters (especially surface properties of natural particles). The usefulness and limits of this kind of approach are illustrated via an application with cadmium, cobalt and caesium using data collected in the Seine, Loire and Gironde estuaries.
\end{abstract}

\section{INTRODUCTION}

Progress in the field of the analysis of trace elements led to a better knowledge of the biogeochemical cycle of contaminants. But, the measurement of the concentration of an element in the various operational fractions (dissolved, particles, colloids...) does not allow a direct knowledge of the various species (free ions, organic and inorganic complexes...) present in the environment. However, this knowledge is necessary to the understanding of the dynamics of the different species, in particular those wich are most bioavailable, and is a prerequisite to the studies of the contaminant effects on the aquatic organisms.

In spite of the accessibility of the littoral environment, the interpretation of field data is not easy and their generalization is difficult because of the spatio-temporal variability of the different processes (physical, chemical and biological) which proceed there.

Mathematical modeling is a good tool to integrate this variability and the diversity of the processes concerned. It makes it possible to synthesize the observations, to understand and treat on a hierarchical basis the phenomena, and in the long term, to evaluate the effects of the modifications of the system on the speciation of the contaminants and their fluxes towards the ocean. This kind of tool must be based on the knowledge of the major processes (on the smallest possible scale) and of the key variables which control them. At present, the geochemical models of speciation make it possible to treat a great number of situations met in aquatic environment. The principal difficulty is related to the evaluation of the various model parameters which cannot be measured directly.

The aim of this paper is to show the usefulness and limits of this kind of approach (experimental evaluation of parameters linked to the sorption properties of natural particles and surface complexation modeling) which are illustrated via an application with cadmium, cobalt and caesium using data collected in the Seine, Loire, Gironde and Rhône estuaries. The data, model and experimental methods used are presented in greater detail in various reports and articles [1-13]. 


\section{MODELING : PRINCIPLE AND REQUIRED DATA}

The Cd, Co, Cs speciation during estuarine transit has been simulated using a surface complexation model (MOCO). The adsorption of $\mathrm{Cd}$ and $\mathrm{Co}$ on particles is treated as a formation of inner sphere complexs with functional surface groups (hydroxyls). Dissolved species are calculated via the solving of the equilibria describing the metal's complexation with various dissolved ligands $\left(\mathrm{Cl}^{-}, \mathrm{OH}^{-}, \mathrm{SO}_{4}^{2 *}\right)$. This approach was detailed in various articles [13-17]. The model used (MOCO) and its application to $\mathrm{Cd}$ in the Seine estuary were presented by Gonzalez et al. [11]. For $\mathrm{Co}$, the cationic exchange is also trated while for $\mathrm{Cs}$ only the cation exchange is considered. The competitor cations taken into account are $\mathrm{C}^{2}$ and $\mathrm{Mg}^{2+}$ for $\mathrm{Co}$ and $\mathrm{K}^{+}$for Cs. The choice of modeled processes is based on studies on $\mathrm{Cd}, \mathrm{Co}$ and $\mathrm{C}$ biogeochemistry in the estuarine environment.

MOCO can consider the various natural particle components (oxyhydroxides, organic matter, clay minerals) as individual adsorbent phases, or treat natural particles in a "global" manner. In this study particles are treated "globally". This approach requires the use of mean sorption properties measured on particles from the various estuaries considered.

\subsection{Required variables and parameters evaluation}

The concentrations of the following variables are required by the model to simulate metals speciation: chlorides (calculated from measured salinity); hydroxides (calculated from $\mathrm{pH}$ ); $\mathrm{SO}_{4}{ }^{2-}, \mathrm{Ca}^{2+}, \mathrm{Mg}^{2+}$ and $\mathrm{K}$ (calculated from salinity, assuming conservativity and using concentrations measured at the fluvial an marine boundaries); suspended matter concentration (SM).

The use of the surface complexation concept requires evaluation of a certain number of parameteri linked to the sorption properties of natural particles. As most of these parameters cannot be measired directly, their evaluation necessitated a variety of experimental approaches [gonzalez et al, 98; gonzalez: al, in press] applied to particle samples taken throughout the estuaries. The parameters used by the mod: are as follows:

- the specific surface area of the particles (SSA in $\mathrm{m}^{2} \mathrm{~g}^{-1}$ ) measured via nitrogen adsorption using ti. BET method (COULTER SA 3100)

- the total concentration of surface exchanging sites of protons ([TS] in $\mathrm{mol} \mathrm{g}^{-1}$ of SM) evaluated by potentiometric acid-base titration (ABT)

- the "mean" intrinsic surface acid-base constants of these sites $\left(\mathrm{K}_{\mathrm{a} 1}\right.$ and $\left.\mathrm{K}_{\mathrm{a} 2}\right)$, determined via adjustment of the experimental data obtained by ABT using FITEQL 3.2 [18-20]

- the "global" intrinsic complexation constant $\left(\mathrm{Km}_{\mathrm{int}}\right)$ of these sites with regards to $\mathrm{Cd}$ and Co obtaini via experiments based on the use of ${ }^{109} \mathrm{Cd}$ and ${ }^{57} \mathrm{Co}$ (particle samples taken throughout the estuary).

- the cation exchange capacity (CEC in mol $\mathrm{g}^{-1}$ of $\mathrm{SM}$ ) estimated via measurements of which uses ammonium as an exchangeable cation.

- the "exchangeable" particulate fraction. The approach used to estimate this fraction [gonzalez et al, in press] is based on the comparison of measured natural metals coefficient of distribution with the coefficient of distribution of their radioactive equivalents (determined by adsorption experiments, on the same samples).

Due to the rough evaluation of the parameters of sorption, and their natural variability within the estuary, we carried out simulations with sets of minimal, mean and maximum values, in order to examine the sensitivity of the model to these significant parameters.

On the basis of these data, the model distributes total measured metals (minus the non exchangeable particulate fraction) among the different considered species. For each field measurement point, a systell of non-linear equations is solved (balance of mass, charges, surface sites and electrostatic effect correction) to calculate concentrations of the various species (dissolved complexes and sorbed) at equilibrium. 
Co in the Seine estuary : Comparison between model results and measurements ( $\mathbf{c}$ Chiffoleau, personal communication ).
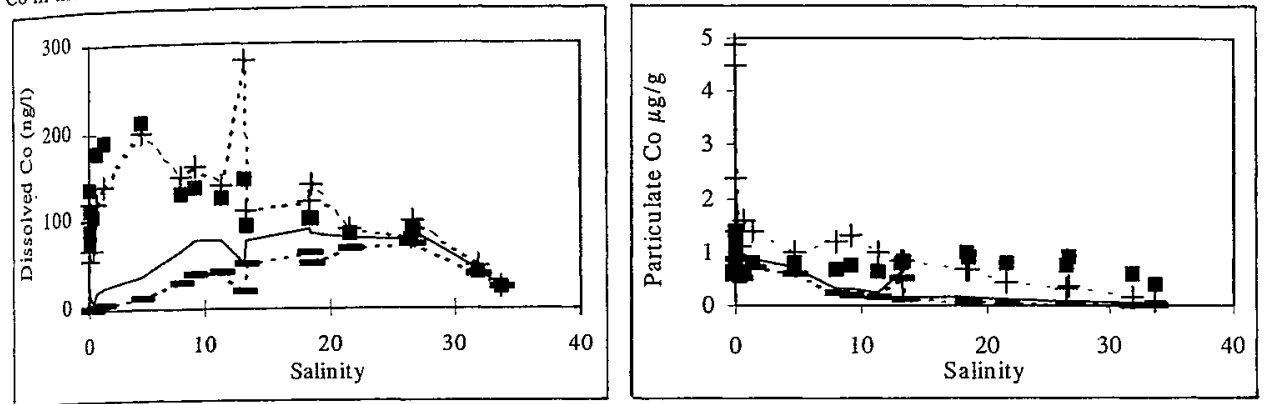

Cd in the Loire estuary : Comparison between model results and measurements ( $\mathbf{n}$ Boutier et al, 1993).
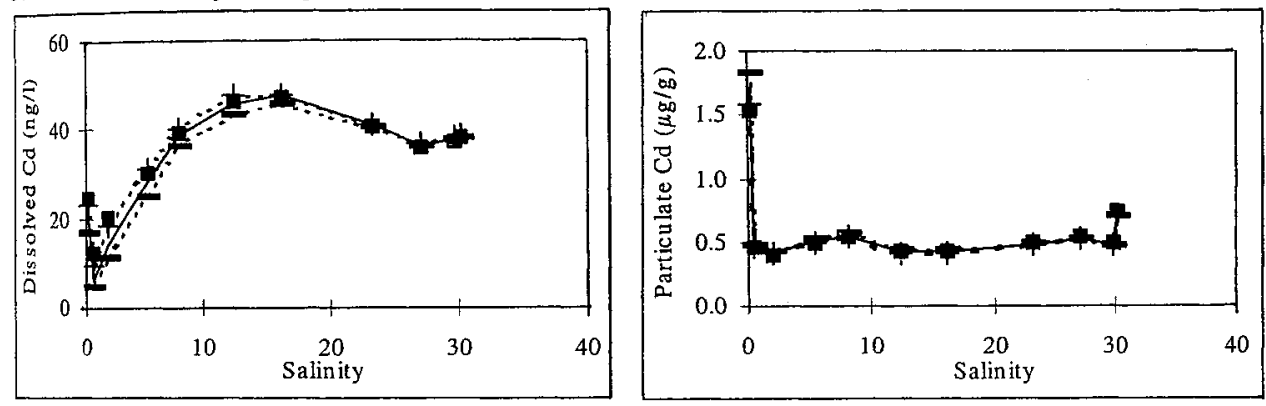

Cd in the Gironde estuary : Comparison between model results and measurements ( $\mathrm{a}$ Boutier et al, 2000).
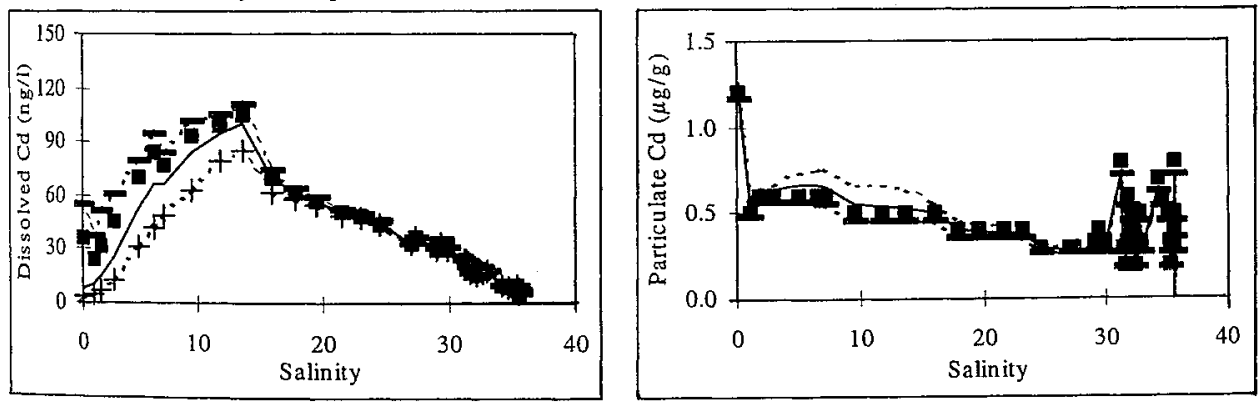

${ }^{134} \mathrm{Cs}$ and ${ }^{137} \mathrm{Cs}$ in the Rhône estuary : Comparison between model results and measurements ( $\mathrm{E}$ Martin and Thomas, 1990).
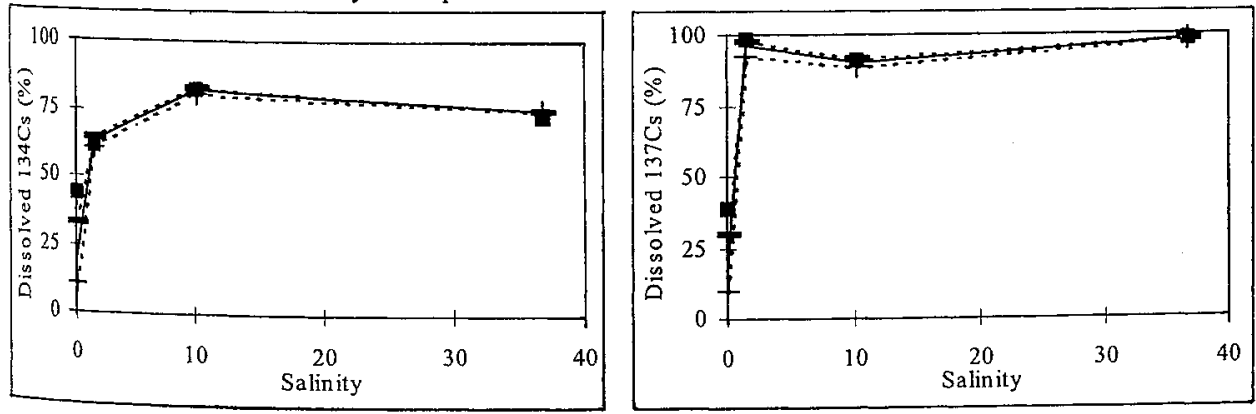

Figure 1 : Examples of simulations for $\mathrm{Cd}, \mathrm{Co}, \mathrm{Cs}$ in the Seine, Loire, Gironde and Rhône estuaries using mean (-), minimum $(-)$ and maximum $(+)$ values of the sorption parameters determined experimentally ( $\mathbf{c}$ measurements). 


\subsection{Comparison of measurements and simulations}

The numerous campaigns realized by IFREMER allowed to obtain the major part of the data necessar for the simulations and for the validation of the model. The figure 1 shows some examples of the obtain? results. To facilitate comparison of the simulation with field measurements, model results are given is "total dissolved cadmium" (sum of the various calculated dissolved species) and particulate $\mathrm{Cl}$ (calculated adsorbed + non-exchangeable).

The results show that metals distribution measured in-situ is comparable to that calculated by the model. Despite its simplifications, MOCO reproduces $\mathrm{Cd}, \mathrm{Co}, \mathrm{Cs}$ behavior and speciation in the estuanis: in a satisfactory manner. One observes a significant solubilization of the three elements as soon as salinity increases:

- for Cd, explained largely by its stability in dissolved chlorocomplexes form and its rapid desoptin during estuarine transit

- due to the competition for the same surface sites with major cations $\left(\mathrm{Ca}^{2+}\right.$ and $\mathrm{Mg}^{2+}$ for $\mathrm{Co}, \mathrm{K}^{+}$for Cs $)$. It should be noted that this process is responsible for the significant Cs solubilization in the plume of the Rhone as soon as salinity increases.

It can exist significant differences between measurements and the results of the model, in particllat for Cd and Co with low salinities and high SM concentrations. It is in these parts that the model is mos sensitive to the value of the sorption parameters and to the quantity of metal exchangeable particulate fraction.

The model's limits are inherent to an efficient evaluation of sorption parameters (in particular wit weak salinities) and the fraction of exchangeable particulate metals (in particular with high concentraiolis of suspended matter).

\section{CONCLUSION}

The application of a surface complexation model to simulate the behavior of $\mathrm{Cd}, \mathrm{Co}$ and $\mathrm{Cs}$ in estuanin environment shows the usefulness and the limits of this approach.

The results indicate that the processes taken into account by the model explain well the dissolved particulate distributions measured. Nevertheless, it can exist important discrepancies between thi measures and the simulations in certain parts of the studied estuaries, particularly for $\mathrm{Cd}$ and $\mathrm{Co}$. Variou: factors can be these gaps, for example:

- a single average type of sorbing particles is considered, their characteristics are little known and considered constant along the estuary

- processes which could be important in certain parts of the estuary (for example: coprecipitation with sulphides in anoxic zones, phytoplanctonic activity in the upstream part) were not taken into account.

The presented approach should be based, in an operational purpose, on the knowledge of numerous parameters estimated on the field or from laboratory experiments. The requirement is to be able to reduce at most the degrees of freedom of the model. A use of this model, in a purpose of forecast, requires 1 coupling to hydrosedimentary transport models $[11,13]$ which reproduce accurately the spatio-tempord distribution of variables (salinity, SM) necessary for the calculations of trace metals speciation.

\section{Acknowledgments}

This work was carried out in the framework of the: «Modélisation du cycle des contaminants » projet (financed by IFREMER); «Seine-Aval » scientific program (financed by the "Haute-Normandie" Regional Council, the "Agence de l'eau Seine-Normandie » and industrial firms in Haute-Normandie) thesis of C. Dange (supported by IFREMER/IPSN grant). We would like to thank B. Boutier and J.F. Chiffoleau for supplying us with most of the data used for the model validation. Thanks also to E. Chartier and D. Auger for their help during the cruises. 


\section{References}

[1] Boutier, B., J. F. Chiffoleau, D. Auger and Truquet I., Est. Cstl. Mar. Sci. 36 (1993) 133-145.

[2] Boutier B., J.F. Chiffoleau, J.L. Gonzalez, P. Lazure, D. Auger and Truquet I., Oceanolo. Acta 23 (2000) 745-757.

[3] Chiffoleau J.F., D. Auger, E. Chartier and Truquet I., in Rapport final 1996 (Programme Scientifique Seine Aval) Thème "Dynamique des contaminants », 1997, pp. 5-23.

[4] Chiffoleau J.F., D. Auger, and Chartier E., in Rapport final 1997 (Programme Scientifique Seine Aval) Thème "Dynamique des contaminants », 1998, pp. 12-27

[5] Chiffoleau J.F., D. Auger and Chartier E., Cont. Shelf Res. 19 (1999) 2063-2082.

[6] Cossa D., M. Meybeck, Z. Idlafkih and Bombled B., in Rapport IFREMER, DEL 94-13, 1994.

[7] Gonzalez J.L. and Thouvenin B., in Rapport final 1995 (Programme Scientifique Seine Aval) Thème "Dynamique des contaminants », 1996, pp. 55-68.

[8] Gonzalez J.L., B. Thouvenin and Tomasino C., in Rapport final 1996 (Programme Scientifique Seine Aval) Thème " Dynamique des contaminants », 1997, pp. 24-40.

[9] Gonzalez J.L., A. Fiandrino and Thouvenin B., in Rapport final 1997 (Programme Scientifique Seine Aval) Thème "Dynamique des contaminants », 1998, pp. 28-60.

[10] Gonzalez J.L., B. Thouvenin, J.F. Chiffoleau and Miramand P., Le cadmium : comportement d'un contaminant métallique en estuaire, edited by IFREMER (Programme Scientifique « Seine Aval », 10, (1999), p. 31.

[11] Gonzalez J.L. , B. Thouvenin, C. Dange, A. Fiandrino, and Chiffoleau J.F., Estuaries (in press).

[12] Martin, J.M. and Thomas A.J., J. Environ. Radioact. 11 (1990) 105-139.

[13] Thouvenin B., J.L. Gonzalez and Boutier B., (1997) Modelling of pollutants behaviour in estuaries.

Mar. Chem. 58 (1997) 147-161.

[14] Stumm W., R. Kummer and Sigg L., Croatia. Chemical. Acta 53 (1980) 291-312.

[15] Westall J.C., in Aquatic surface chemistry, edited by Stumm W. (1987), pp. 3-31.

[16] Davis J.A. and Kent D.B., in Mineral-water interface geochemistry, edited by Hochella M.F. and White A.F. (Reviews in Mineralogy, 23, 1990), pp. 177-260.

[17] Dzombak, D.A. and Morel F.M.M., Surface complexation modeling: Hydrous ferric oxide, edited by John Wiley (New York, 1990).

[18] Westall J.C., FITEQL - A computer program for determination of chemical equilibrium constants from experimental data, edited by Oregon State University (Corvallis, 1982).

[19] Gulmini M., V. Zelano, P. G. Daniele, E. Prenesti and Ostacoli G., Anal. Chim. Acta 329 (1996) 3339.

[20] Wang F., J. Chen, J. Chen and Forsling W., Water Res. 31 (1997) 796-1800. 